\title{
Using Variable Piston Trajectory to Reduce Engine-out Emissions
}

Chen Zhang, Zongxuan Sun ${ }^{1}$

Department of Mechanical Engineering, University of Minnesota, Twin Cities Campus,

111 Church Street SE, Minneapolis, MN 55455

\begin{abstract}
Previously, the authors have proposed the concept of piston trajectory-based combustion control enabled by free piston engines (FPES). With this novel method, the FPE realizes in-cycle adjustment of combustion phase and real-time control of in-cylinder temperature and pressure through variable piston trajectories. As a result, higher indicated thermal efficiency, compared to conventional internal combustion engines (ICES), is achieved. In this paper, the effects of this new combustion control on engine-out emissions are investigated. First, a comprehensive model is developed that includes different piston trajectories in the FPE, a convective heat loss model and a reduced n-heptane reaction mechanism with major emissions species. Afterwards, the chemical kinetics of CO and NOx emissions are described in details that reveal the feasibility of reducing engine-out emissions by employing novel piston trajectories. At last, analyses of the corresponding simulation results and comparisons of emissions and thermal efficiencies between the FPE and conventional ICEs are presented, which further shows the advantages of the trajectory-based combustion control.
\end{abstract}

Keywords: Emissions control, Dynamic modelling, Free piston engine, Trajectory-based combustion control.

\footnotetext{
${ }^{1}$ Corresponding author. Tel.: +01 612-625-2107

E-mail address: zsun@umn.edu (Zongxuan Sun)
} 


\section{Introduction}

Investigations of cleaner and more efficient ways for transportation energy usage have attracted more and more public attentions to date due to the increasing concerns on the environmental issues and the future energy supply. Currently, vehicle propulsion systems are still dominated by conventional internal combustion engines (ICEs), a technology invented more than a century ago. Although significant progresses have been made, the overall efficiency of the ICE is still under the requirement while the room for further improvement is limited. Furthermore, such limitation is exacerbated if taking the engine emissions performance into account.

Typically, the term "engine emissions" refers to several components in the engine exhaust, including carbon monoxide (CO), various oxides of nitrogen (NOx), unburnt hydrocarbons $(\mathrm{HC})$, and particulate matter (PM). It is widely-known that unlimited release of these pollutants would cause formidable damages to both human health and environment $[1,2]$. As a result, more and more countries and regions have provided or followed increasingly stringent emissions regulations [3, 4].

Technologies to reduce emissions are mainly separated into two categories. One is aimed to optimize the combustion processes inside the ICE and reduces so-called "engine-out" emissions directly. Extensive researches have been conducted on this approach and several technologies, including retarding the ignition time [5-7], exhaust gas recirculation (EGR) [8-11] and advanced fuel injection strategy [12-15], have been widely adopted in real world applications. However, the reductions of emissions achieved by these methods are limited, especially if higher engine efficiency and fuel economy are required. For instance, it was reported that between 5\% and 10\% EGR in the spark-ignition (SI) engine could reduce almost half NOx emission in specific working conditions [16]. Nonetheless, this NOx reduction is achieved by adding large amounts of inert gases into the intake air-fuel mixture and therefore reducing the combustion rate and peak temperature. As a result, the EGR method decreases the maximal achievable power in high load, increases the fuel consumption in elevated load and causes unstable combustion or even misfire in low load or idle condition.

The other approach is to reduce the engine emissions through advanced aftertreatment systems. Such method receives great success in vehicles powered by SI engines since its air-fuel mixture remains at stoichiometric ratio for the majority of loading conditions [17]. This feature ensures the effectiveness of the three-way catalyst converter which decreases the tail-out production of $\mathrm{CO}, \mathrm{HC}$ and $\mathrm{NOx}$ simultaneously. Unfortunately, this system possess a severe cold-start problem [18-20] and also fails to regulate the emissions performance while engine is in transient (e.g. acceleration) conditions [21, 22]. On the other hand, comprehensive aftertreatment system for compression-ignition (CI) engine is still an open question which asks for further research. The existing three-way catalyst converter cannot be adopted in diesel engines directly due to the following two reasons: first, diesel engines usually operate in fuel-lean condition; second, the exhaust from the diesel engine contains large amounts of PM and other organic compounds which poison the catalyst easily. Other methods, such as diesel oxidation catalyst $[23,24]$, diesel particulate filter $[25,26]$ and selective catalytic reduction [27] are also proposed, but those systems are quite complicated due to their strong temperature dependence while the corresponding manufacture costs also increase significantly.

Hence, existing emission controls in conventional ICE may not be able to optimize the combustion processes and reduce the pollutants under the entire engine operation domain. As a consequence, revolutionary technical innovation is required to transform the conventional ICE into a much cleaner and more flexible energy conversion device.

Free piston engine (FPE), with a totally different architecture, is considered as one of the most promising alternatives of conventional ICEs [28-37]. Without the constraints caused by the mechanical crankshaft, the FPE enables the ultimate freedom of piston motion and be able to generate variable piston trajectories. As a result, the FPE is able to utilize this variable trajectory as an additional control means to enhance the engine performance. The main technical barrier for the mass production of this technology is the lack of precise and robust piston motion control since the piston movement is determined by the combustion force and the load dynamics in real-time [34, 35, 38-42]. Previously, an active control, named as "virtual crankshaft", has been developed by the authors and implemented on a prototype hydraulic FPE (Fig. 1). The "virtual crankshaft" mechanism is achieved by controlling the opening of the servo valve and therefore manipulating the hydraulic forces acting on the pistons. Consequently, the piston motion can be controlled to precisely track the desired reference trajectories $[34,35]$.

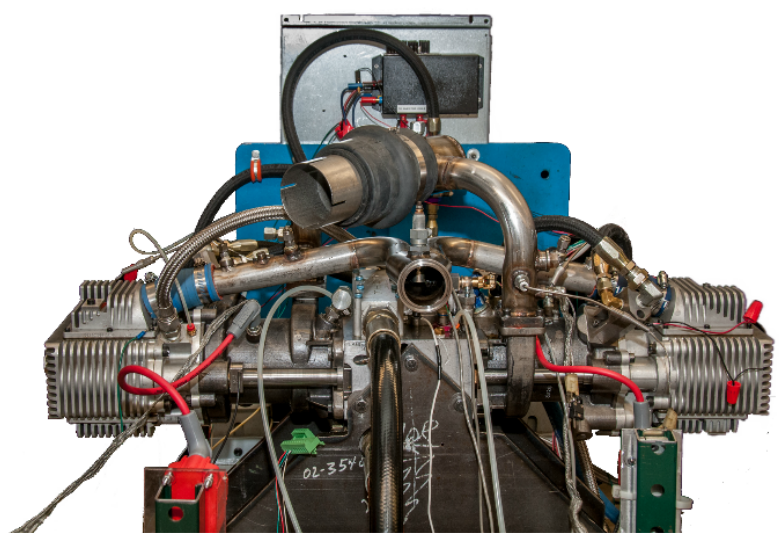

Figure 1. Picture of the Free Piston Engine at University of Minnesota.

With the capability of generating various piston trajectories, the FPE is expected to tailor the combustion processes in real-time and optimize the combustion outputs by implementing the optimal piston trajectory, which forms the basic concept of trajectory-based combustion control. This expectation is rational since the combustion process is determined by the interactions between the gas dynamics and the fuel chemical kinetics through a feedback manner (Fig. 2). The optimal piston trajectory can be designed and generates 
the most appropriate volume profile to affect the aforementioned interactions. Previously, the authors have investigated the effects of various trajectories on the engine performance and showed that the trajectory-based combustion control enabled by FPE is able to adjust combustion phasing, reduce the heat loss and therefore increase the indicated thermal efficiency [43]. However, few results have been shown previously to reveal the benefit of the advanced combustion control on emissions reduction.

In this paper, the effects of the trajectory-based combustion control on engine emissions are investigated and a new approach, reducing the engine-out emissions by employing asymmetric piston trajectories, is proposed. A system model, including a physical-based model representing the FPE operation and a reduced n-heptane reaction mechanism [44], is developed which demonstrates the feasibility of this new approach. The corresponding simulation results show the trajectory's positive influences on the engineout emissions, indicating the advantages of the trajectorybased combustion control.

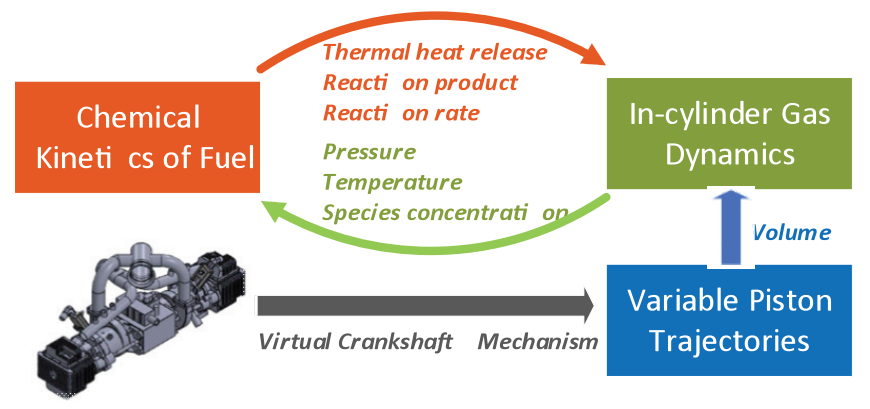

Figure 2. Interaction between chemical kinetics and gas dynamics.

\section{Modeling Approach}

The model is developed by assuming the combustion chamber of the FPE as a homogeneous variable-volume reactor. Additionally, the scavenging process is neglected and air-fuel mixture is presumed to be well-stirred initially in the reactor. The detailed modeling approach is presented as follow: First, a method aimed to generate various piston trajectories in the FPE is presented. Secondly, a physics-based model is constructed using the first law of thermodynamics and convective heat transfer process. Afterwards, a reduced nheptane mechanism [44] is employed to reproduce the combustion process and emissions production. Finally, the modeling tools used to integrate the above subsystems into a completed model and simulate the engine performance are introduced.

\subsection{Variable Piston Trajectories}

Due to the elimination of the mechanical crankshaft, the piston movement in the FPE completely relies on the combination of all the forces acting on the piston, including the in-cylinder gas force and the variable loading force. As a result, arbitrary piston trajectory can be achieved if the corresponding force combination is designed and implemented into the FPE. However, this freedom inevitably increases the control difficulty since any abnormal combustion phenomena, e.g. misfire, can easily corrupt the prescribed force combination and cause the engine stall. Therefore, an active control which enables rapid adjustment on actuation force according to the tracking error is desired. Such a control, named as the "virtual crankshaft" mechanism, was developed and verified experimentally by the authors previously [34, 35], so that continuously variable compression ratio (CR) and adjustable motion pattern between the bottom dead center (BDC) and the top dead center (TDC) can be achieved.

In order to represent this ultimate freedom of piston motion in the FPE, a new description was proposed by the authors previously in [43]. In this method, the piston movement in the FPE is described as the $\mathrm{x}$-axis displacement of a point moving around an ellipse in a counter clockwise direction, as shown in the left of Fig. 3.

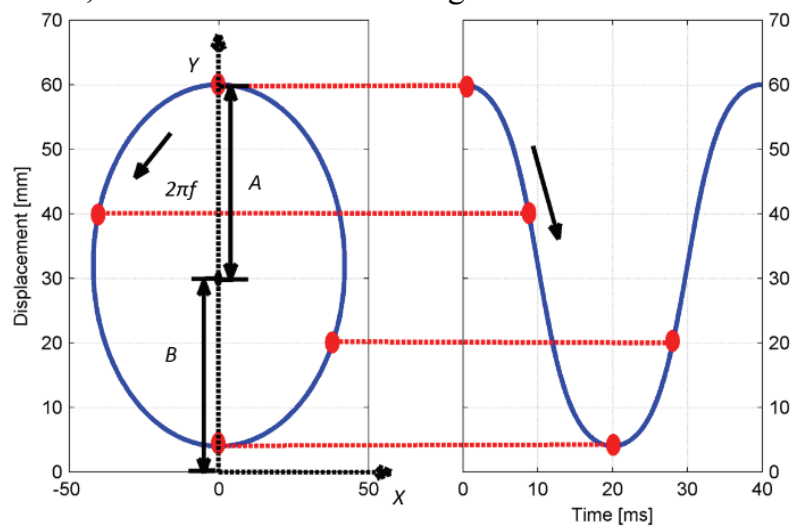

Figure 3. Description of FPE piston motions (Left: the point moves around the ellipse, Right: the corresponding piston trajectory).

The corresponding piston trajectory can be derived:

$$
X=\frac{A \cdot \Omega \cdot \cos (2 \pi f \cdot t)}{\sqrt{\Omega^{2} \cdot \cos (2 \pi f \cdot t)^{2}+\sin (2 \pi f \cdot t)^{2}}}+B
$$

while $A$ and $B$ identify the locations of the TDC and the BDC and therefore the value of CR. $f$ and $\Omega$ show the frequency of the piston movement and its motion pattern between the TDC and the BDC respectively. $t$ stands for time.

It is worth noting that by changing the value of $\Omega$, different piston motion patterns between the same TDC point and BDC point can be achieved in the FPE with virtual crankshaft mechanism, as shown in Fig. 4.

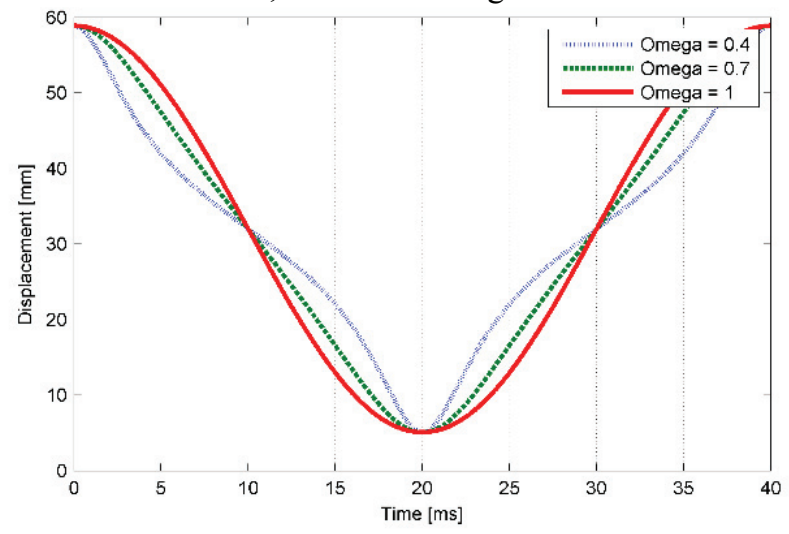

Figure 4. Various piston trajectories with different $\Omega$. 
Additionally, due to the ultimate freedom of the piston movement in the FPE, the piston trajectory can even be asymmetric. In other words, the compression process and the expansion process of the FPE can be totally distinct with each other. As shown in Fig. 5, three trajectories are depicted with the identical compression process, but different expansion processes indicated by various $\Omega$ afterwards. The variation of $\Omega$ in each trajectory occurs at the TDC point (indicated by $20 \mathrm{~ms}$ point since the FPE operation frequency is $25 \mathrm{~Hz}$ in this study) which ensures the smooth transition. This unique feature in the FPE realizes the in-cycle combustion control by assigning different control objectives on the designing of each trajectory section. For example, the compression process can be determined by optimizing the combustion phase and the expansion process can be designed to reduce the heat loss and NOx emission. Further discussion will be presented in Section 4 in this paper.

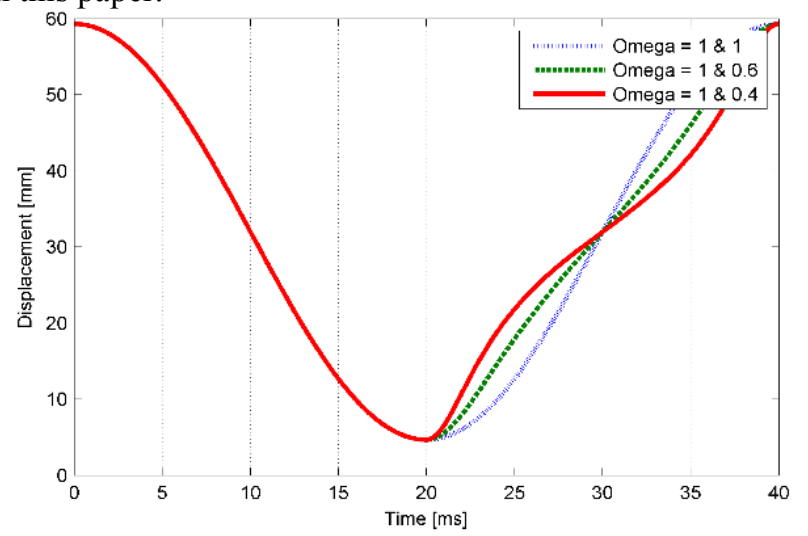

Figure 5. Asymmetric trajectories generated by the FPE (identical compression processes but different expansion processes).

\subsection{Physics-based Model}

The development of the physics-based model mainly follows the process in [43]. The combustion chamber is modeled as a closed thermodynamic system using the energy and species mass conservation equations as below:

$$
\begin{aligned}
\frac{d U}{d t}= & -P \frac{d V}{d t}-\dot{Q}_{H T}+\dot{Q}_{\text {Chem }} \\
& m \frac{d \omega_{i}}{d t}=\dot{m}_{i, \text { chem }} \quad i=1,2 \ldots N_{s}
\end{aligned}
$$

The left term in (2) represents the time-derivative of the internal energy. The three terms on its right side are the volumetric work, heat loss through the engine wall and the heat release from the chemical reactions, respectively.

In (3), $m$ is the total mass of the air-fuel mixture which is determined initially. $N_{s}$ is the total number of species in the employed reaction mechanism and $\omega_{i}$ represents the mass fraction of species $i$. The right term in (3) shows the net production rate of species $i$ in mass-scale generated by the involved reactions.

By assuming the heat loss process being convective, the heat loss term can be yielded as:

$$
\dot{Q}_{H T}=h \cdot A_{\text {wall }}\left(T-T_{\text {wall }}\right)
$$

where $A_{\text {wall }}$ is the surface area around the combustion chamber, $T_{\text {wall }}$ is the wall temperature, $T$ is the in-cylinder gas temperature and $h$ is the heat transfer coefficient, which is calculated via the modified Woschni correlation [17]:

$$
h=3.26 \cdot b^{-0.2} P^{0.8} T^{-0.55} w^{0.8}
$$

where $b$ represents the engine bore, $P$ is the pressure of the incylinder gas, and $w$ is the average in-cylinder gas velocity. The values of these parameters, such as $T_{\text {wall }}, b$ and $w$, can be found in [43].

The ideal-gas law is also applied here to calculate the variation of the internal energy $d U / d t$ and the in-cylinder pressure $P$, using the in-cylinder temperature $T$, constant volume heat capacity of each species $C_{v, i}$, mass fraction of each species $\omega_{i}$, gas constant of each species $R_{i}$, total mass $m$ and chamber volume $V$ :

$$
\begin{gathered}
\frac{d U}{d t}=\sum_{i=1}^{N_{s}} C_{v, i} \cdot m \cdot \omega_{i} \frac{d T}{d t}+\sum_{i=1}^{N_{s}} C_{v, i} \cdot m \cdot T \cdot \frac{d \omega_{i}}{d t} \\
P \cdot V=m \cdot R_{\text {mass }} \cdot T \\
R_{\text {mass }}=\sum_{i=1}^{N_{s}} R_{i} \cdot \omega_{i}
\end{gathered}
$$

\subsection{Chemical Reaction Mechanism}

A proper chemical reaction mechanism is necessary to calculate the following terms in (2), (3) and (6) by providing thermal data of each species and chemical kinetics:

$$
\begin{array}{r}
\dot{Q}_{\text {Chem }}=-V \cdot \sum_{i=1}^{N_{i}} v_{i} \cdot h_{i, m} \\
m \frac{d \omega_{i}}{d t}=\dot{m}_{i, \text { hem }}=V \cdot M_{i} \cdot v_{i}
\end{array}
$$

where $v_{i}, M_{i}$ and $h_{i, m}$ denote the net production rate, molar weight and the molar enthalpy of specie $i$ respectively.

Generally, a reaction mechanism includes a completed NASA polynomial parametrization which represents the constant volume heat capacity $C_{v, i}$, molar enthalpy $h_{i, m}$ and molar entropy $S_{i, m}$ of each species as functions of in-cylinder temperature [45]. Furthermore, the chemical kinetics described in the reaction mechanism can be utilized to compute $v_{i}$ in (9) and (10). A representative calculation process is shown in [43] as well.

The reaction mechanism utilized in the proposed model is a reduced n-heptane reaction mechanism [44]. This mechanism is first developed by embedding several sub mechanisms such as the GRI NOx mechanism and a detailed poly-aromatic hydrocarbon (PAH) mechanism, into a base nheptane mechanism. Afterwards, various mechanism reduction methods, including the direct relation graph error propagation (DRGEP) and reaction pathways analysis, are applied to reduce the size of the entire mechanism to 76 species and 366 reactions. Consequently, the generated mechanism not only captures the essential feature of the chemical kinetics reproduced by these detailed reaction mechanisms, but also improves computational efficiency significantly. The effectiveness of this reaction mechanism, in terms of the predictions of ignition delay time and flame propagation speed, has been experimentally validated by different facilities, e.g. shock tube, constant volume chamber and test-bed engine [44]. 
The chemical kinetics of each emission species can be achieved through the reaction mechanism as well. The base nheptane mechanism contains elementary reactions which represent the pyrolysis process of $n$-heptane molecule at low and elevated temperature. These reactions form the governing chemical kinetics for the generation of unburned HC; The $\mathrm{PAH}$ mechanism, describing the formation of $\mathrm{PAH}$ up to four rings which are the major precursors of the soot emission, is also included in the applied reaction mechanism.

Additionally, the applied reaction mechanism contains 42 reactions involved production and consumption of $\mathrm{CO}$ and all of them are listed in the appendix at the end of this paper. In order to capture the essence of the $\mathrm{CO}$ chemical kinetics, sensitivity analysis are further conducted among these 42 reactions. Generally, the sensitivity analysis is the process of calculating the normalized sensitivity coefficient $S_{i}$ for the involved reactions, which can be yielded as:

$$
S_{i}=\frac{P_{i}}{\omega_{C O}} \frac{\partial \omega_{C O}}{\partial P_{i}}
$$

while $\omega_{C O}$ represents the concentration of $\mathrm{CO}$ and $P_{i}$ is a multiplier on the forward rate constant of $i$ th reaction.

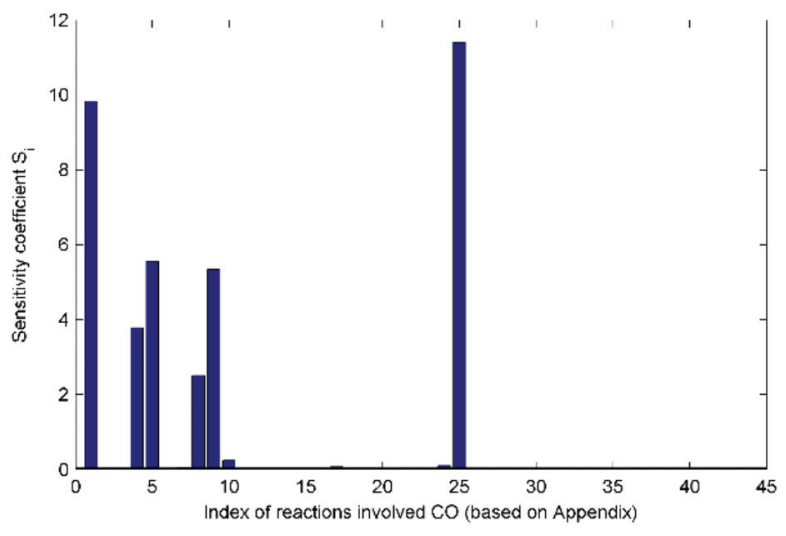

Figure 6. Sensitivity analysis for 42 reactions involved $\mathrm{CO}$.

The corresponding result of this sensitivity analysis is shown in Fig. 6 and the selected 10 elementary reactions, whose sensitivity coefficients $S_{i}$ are larger than 0.05 , are listed in Table. 1. The index of the related reactions are refer to the number in the appendix at the end of this paper.

Table. 1 Governing reactions for $\mathrm{CO}$ chemical kinetics.

\begin{tabular}{|c|}
\hline Selected Elementary Reactions \\
\hline $\mathrm{C} 5 \mathrm{H} 11 \mathrm{CO}<=>\mathrm{C} 2 \mathrm{H} 4+\mathrm{C} 3 \mathrm{H} 7+\mathrm{CO}$ \\
\hline $\mathrm{CH} 3 \mathrm{O}+\mathrm{CO}<=>\mathrm{CH} 3+\mathrm{CO} 2$ \\
\hline $\mathrm{CO}+\mathrm{OH}<=>\mathrm{CO} 2+\mathrm{H}$ \\
\hline $\mathrm{CO}+\mathrm{HO} 2<=>\mathrm{CO} 2+\mathrm{OH}$ \\
\hline $\mathrm{HCO}+\mathrm{O} 2<=>\mathrm{CO}+\mathrm{HO} 2$ \\
\hline $\mathrm{HCO}(+\mathrm{M})<=>\mathrm{CO}+\mathrm{H}(+\mathrm{M})$ \\
\hline $\mathrm{HCO}+\mathrm{OH}<=>\mathrm{CO}+\mathrm{H} 2 \mathrm{O}$ \\
\hline $\mathrm{CH} 2 \mathrm{CHO}+\mathrm{O} 2<=>\mathrm{CH} 2 \mathrm{O}+\mathrm{CO}+\mathrm{OH}$ \\
\hline $\mathrm{CH} 2 \mathrm{CHO}(+\mathrm{M})<=>\mathrm{CH} 3+\mathrm{CO}(+\mathrm{M})$ \\
\hline $\mathrm{CH} 3 \mathrm{CO}(+\mathrm{M})<=>\mathrm{CH} 3+\mathrm{CO}(+\mathrm{M})$ \\
\hline
\end{tabular}

The included GRI NOx mechanism in the employed reaction mechanism is built upon the Zeldovich mechanism [46] plus the generation processes of $\mathrm{N}_{2} \mathrm{O}$ and $\mathrm{NO}_{2}$, which consist of 11 elementary reactions (as can be seen in Table.2).
Extensive researches have been conducted to demonstrate the capability of this mechanism predicting accurate NOx emission in the real world applications [47].

Table. 2 Governing reactions for NOx chemical kinetics.

\begin{tabular}{|c|}
\hline Selected Elementary Reactions \\
\hline $\mathrm{N} 2+\mathrm{O}<=>\mathrm{N}+\mathrm{NO}$ \\
\hline $\mathrm{N}+\mathrm{O} 2<=>\mathrm{NO}+\mathrm{O}$ \\
\hline $\mathrm{N}+\mathrm{OH}<=>\mathrm{H}+\mathrm{NO}$ \\
\hline $\mathrm{N} 2+\mathrm{O} 2<=>\mathrm{N} 2 \mathrm{O}+\mathrm{O}$ \\
\hline $\mathrm{N} 2 \mathrm{O}+\mathrm{O}<=>2 \mathrm{NO}$ \\
\hline $\mathrm{N} 2+\mathrm{OH}<=>\mathrm{H}+\mathrm{N} 2 \mathrm{O}$ \\
\hline $\mathrm{HO} 2+\mathrm{N} 2<=>\mathrm{N} 2 \mathrm{O}+\mathrm{OH}$ \\
\hline $\mathrm{HO} 2+\mathrm{NO}<=>\mathrm{NO} 2+\mathrm{OH}$ \\
\hline $\mathrm{NO}+\mathrm{O}(+\mathrm{M})<=>\mathrm{NO} 2(+\mathrm{M})$ \\
\hline $\mathrm{NO} 2+\mathrm{O}<=>\mathrm{NO}+\mathrm{O} 2$ \\
\hline $\mathrm{H}+\mathrm{NO} 2<=>\mathrm{NO}+\mathrm{OH}$ \\
\hline
\end{tabular}

In this paper, the simulation work mainly focuses on the piston trajectory effects on $\mathrm{CO}$ and NOx emissions. Other emission species will be investigated in the future study.

\subsection{Modeling Tools}

With the capability of readily extracting thermal data and chemical kinetics from the existing reaction mechanisms, Cantera is considered as one of the most widely-used software packages to deal with the projects involving the chemical, thermodynamic and kinetics calculation [45]. In this study, it is used to integrate the reduced n-heptane reaction mechanism with the physical-based model and simulate the combustion processes along variable piston trajectories within the Python environment. The generated data is then sent to Matlab $\mathrm{R} 2012 \mathrm{~b}$ for further processing and imaging. All of the software are working within a laptop with $2.60 \mathrm{GHz}$ Inter(R) Core ${ }^{\mathrm{TM}} \mathrm{i} 5-3230 \mathrm{M}$ processor and $4.00 \mathrm{~GB}$ installed memory.

\section{New Approach to Reduce Engine-out Emissions}

In [43], the authors have shown that varying the piston motion patterns between the TDC and the BDC point, indicated by the value of $\Omega$, enables the adjustment of the combustion processes in terms of manipulating the combustion phasing, reducing the heat loss and increasing the indicated thermal efficiency. This idea is clearly presented in the block diagram of the trajectory-based combustion control, as shown in Fig. 7.

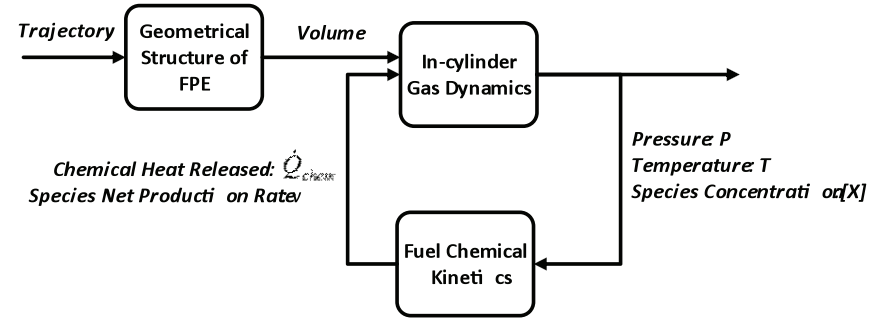

Figure 7. Block diagram of the trajectory-based combustion control.

Apparently, the piston trajectory works as an input to the entire dynamic system and produces different volume profiles accordingly. Afterwards, these variable volume profiles are sent to the feedback loop and influence the interactions 
between the in-cylinder gas dynamics and the fuel chemical kinetics. Eventually, the system outputs are generated in terms of pressure, temperature and species concentrations.

Considering the fact that production of emissions are also included in the species concentration outputs, the capability of tailoring the combustion in FPE by varying piston trajectories implies a new approach to reduce the emissions.

As can be seen in Fig. 8, three piston trajectories with identical compression ratio $(\mathrm{CR}=11)$ but different $\Omega$ (show in Fig. 4) generate completely distinct combustion processes. The air-fuel equivalence ratio (AFER) of the mixture in each case is fixed at 2 . It is evident that the trajectory with $\Omega=0.4$ cannot ignite the intake mixture at all, which produces large amount of unburned hydrocarbon emission inevitably. However, increasing $\Omega$ to 0.7 generates an uncompleted combustion process and converts the unburned hydrocarbon to both $\mathrm{CO}$ and $\mathrm{CO}_{2}$. A completed combustion process is eventually formed if $\Omega$ is increased to 1 and almost all the fuel molecules are converted to final product $\mathrm{CO}_{2}$. In the last case, the peak temperature of the in-cylinder gas reaches over $2100 \mathrm{~K}$ indicating the total chemical energy of the fuel has been released through the oxidation of $\mathrm{CO}$ to $\mathrm{CO}_{2}$.

These different combustion processes can be explained since larger $\Omega$ of piston trajectory has longer resident time when the piston locates around the TDC point, which offers longer period to accumulate the necessary radical species and trigger the combustion. In other word, piston trajectory with great $\Omega$ provides beneficial environment for the air-fuel mixture ignition while small $\Omega$ inhibits the accumulation of radical species and postpones the start of combustion or even causes misfire. In other words, the piston trajectory with large $\Omega$ ensures the completed oxidation of fuel molecule to $\mathrm{CO}_{2}$ and therefore reduces the emissions such as $\mathrm{CO}$ and unburned HC.

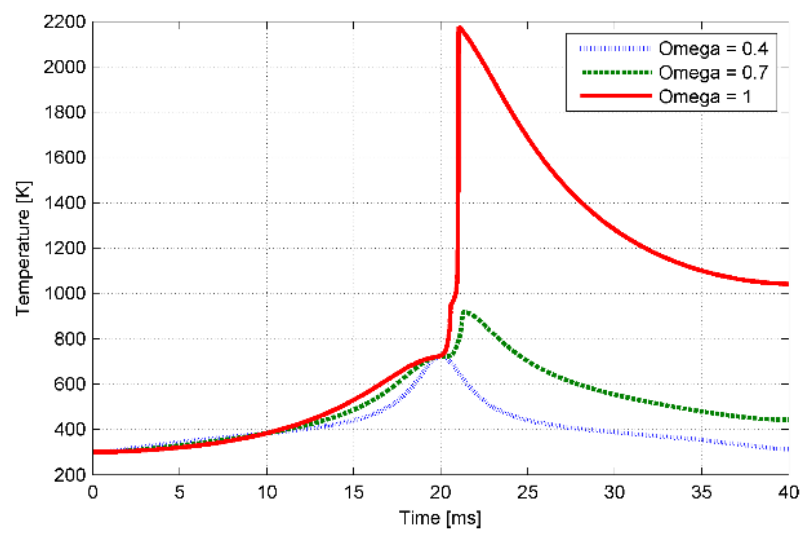

Figure 8. Temperatures traces along the piston trajectories in Fig. 4.

Additionally, the ultimate freedom of the piston movement in FPE also enables the implementation of asymmetric piston trajectories, as shown in Fig. 5. In other words, the compression and expansion sections can be synthesized for different objectives respectively. For example, the compression trajectory is designed to trigger the combustion occurring at the TDC point which forms the approximate ideal Otto cycle and guarantees the minimum production of $\mathrm{CO}$ and unburned $\mathrm{HC}$; the expansion trajectory is developed to reduce the in-cylinder gas temperature right after the combustion. In this way, not only the heat loss, but also the NOx emission, which is sensitive to temperature, can be decreased. The piston trajectories in Fig. 5 are generated based on these two requirements and the corresponding temperature profiles are shown in Fig. 9.

It is apparent in Fig. 9 that each peak temperature is located at the TDC point in all the three cases, which means the combustions are all completed before the beginning of the expansion processes. Additionally, the temperature traces after the TDC point are distinct with each other due to the different expansion processes. The in-cylinder temperature reduces faster after the peak temperature in the third case (solid line) compared to the others. This result is intuitive since the third piston trajectory (presented as the solid line in Fig. 5) expands more quickly than the other two, which increases the volume of the combustion chamber and cools down the gas temperature more rapidly. Since all the chemical energy has already been extracted at the TDC point, shorter period of higher temperature in the cylinder lowers the dissipation of the thermal energy and enhances the indicated thermal efficiency. The calculated thermal efficiencies for the three cases support the conclusion above, as can be seen in the inserted box inside Fig. 9. Additionally, the reduced in-cylinder temperature also decreases the production of NOx. The detailed explanation of the reduction of $\mathrm{NOx}$ and $\mathrm{CO}$ emission, from the perspective of chemical kinetics, will be shown in the next section.

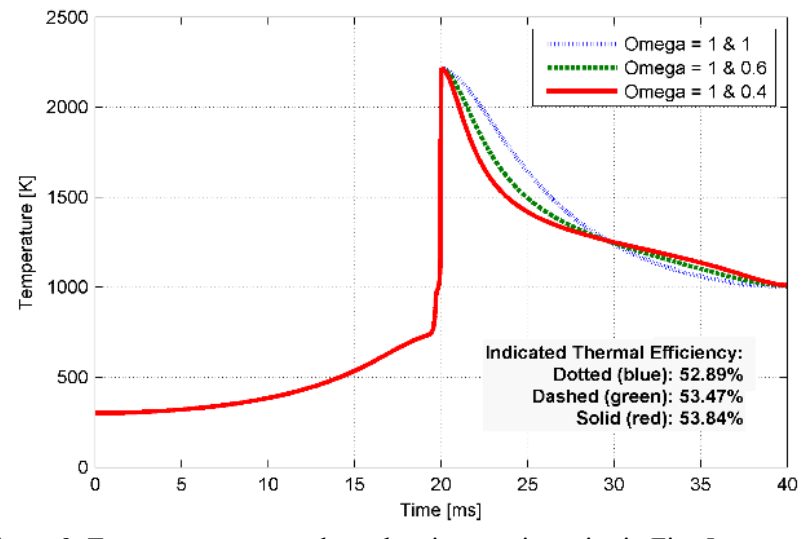

Figure 9. Temperature traces along the piston trajectories in Fig. 5.

\section{Simulation Result and Discussion}

\subsection{CO Emission}

The production of $\mathrm{CO}$ emission is mainly due to the uncompleted combustion. In other words, not all the carbon atoms in the fuel molecules are converted to the final product $\mathrm{CO}_{2}$ but generate some other products including unburned $\mathrm{HC}$ and $\mathrm{CO}$. One of the critical reasons causes the uncompleted combustion in HCCI combustion is the utilization of fuel-rich mixture. If the AFER is less than 1, insufficient oxygen is involved in the combustion process and the carbon atoms can only be partially oxidized to $\mathrm{CO}$, which produces significant $\mathrm{CO}$ emission. As a result, operating the FPE in the fuel-lean condition is able to reduce $\mathrm{CO}$ emission.

However, even in the fuel-lean condition, the completed combustion process is still not guaranteed. As illustrated in 
Fig. 8, misfire or uncompleted combustion still exist though the AFER $\lambda$ equals 2 . Fortunately, the piston trajectories in the FPE can be adjusted in order to ensure the completed oxidation of carbon atoms in the fuel molecules.

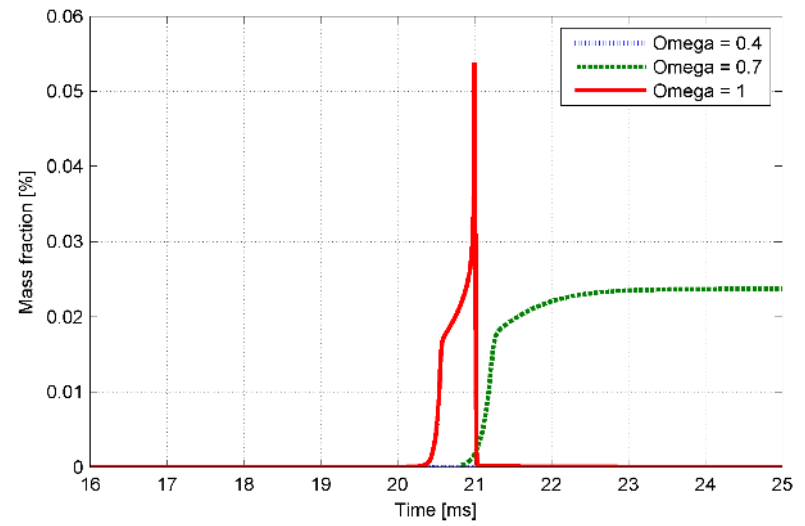

Figure 10. CO concentration traces during the combustion processes in Fig. 8.

Fig. 10 displays the corresponding $\mathrm{CO}$ traces during the combustion processes shown in Fig. 8. Due to the misfire in the trajectory with $\Omega=0.4$, the low temperature cannot broke up the majority of fuel molecules to smaller hydrocarbon, e.g. aldehyde. As a result, very few $\mathrm{CO}$ is generated through the low temperature pyrolysis reactions at pretty slow rates and significant unburned HC is produced, as shown in Fig 11(a).

In the second case whose piston trajectory with $\Omega=0.7$, an uncompleted combustion occurs (Fig. 10) and great amount of $\mathrm{CO}$ (over $0.02 \%$ in mass fraction scale) is produced mainly by the following reactions (Fig. 11(b)):

$$
\begin{aligned}
& \mathrm{C}_{5} \mathrm{H}_{11} \mathrm{CO} \leftrightarrow \mathrm{C}_{2} \mathrm{H}_{4}+\mathrm{C}_{3} \mathrm{H}_{7}+\mathrm{CO} \\
& \mathrm{HCO}+\mathrm{O}_{2} \leftrightarrow \mathrm{CO}+\mathrm{HO}_{2}
\end{aligned}
$$

However, the major $\mathrm{CO}$ consumption reaction:

$$
\mathrm{CO}+\mathrm{OH} \leftrightarrow \mathrm{CO}_{2}+\mathrm{H}
$$

are not trigged due to the relatively low temperature and insufficient radical species. Thus, the large amount of $\mathrm{CO}$ is not converted to $\mathrm{CO}_{2}$ but maintained as the emission eventually.

The last case forms a completed combustion after the TDC point. As the solid line shown in Fig. 10, almost all the carbon atoms are converted to $\mathrm{CO}$ right before $21 \mathrm{~ms}$ and subsequently oxidized to $\mathrm{CO}_{2}$ rapidly. The corresponding chemical kinetics of this process is shown in Fig. 11(c), presenting the major reactions involved in this process. The major CO consumption reaction (14), as well as the major heat release reaction during the combustion process, are dominant during the entire process. Consequently, the final production of $\mathrm{CO}$, in this case, is only $2.22 \mathrm{e}-7 \%$ in mass fraction scale. As mentioned in the last section, piston trajectory with greater $\Omega$ provides favorable environment to trigger the combustion by locating the piston around the TDC point for longer duration. On the other hand, advanced start of combustion timing also implies longer period of high temperature incylinder which increases chemical reaction rates and improves the completeness of combustion.

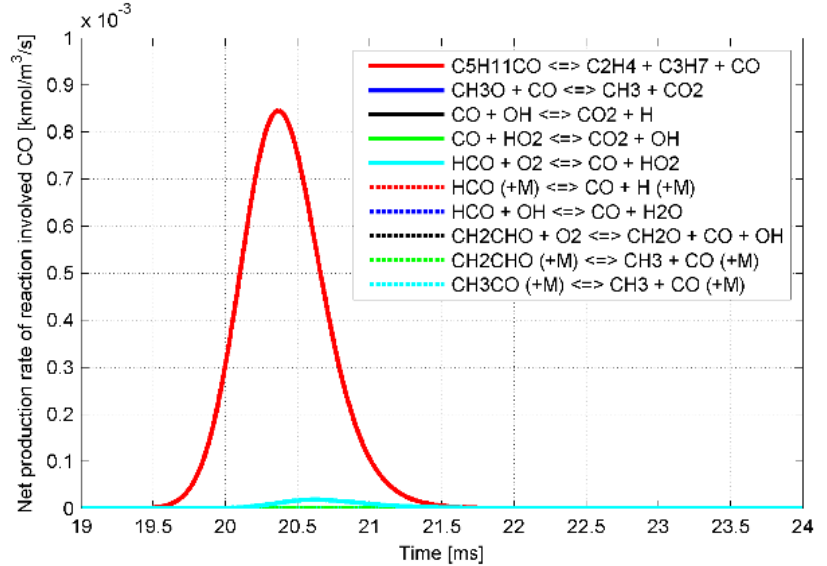

(a)

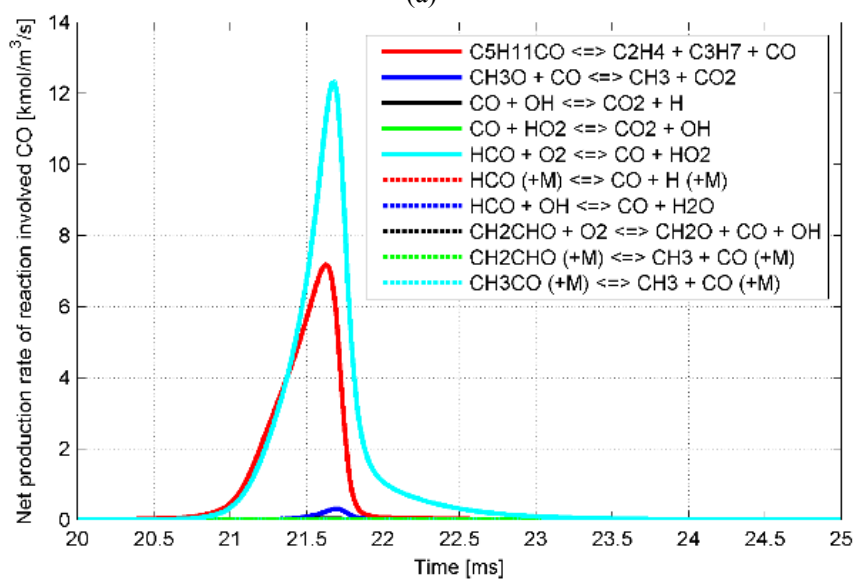

(b)

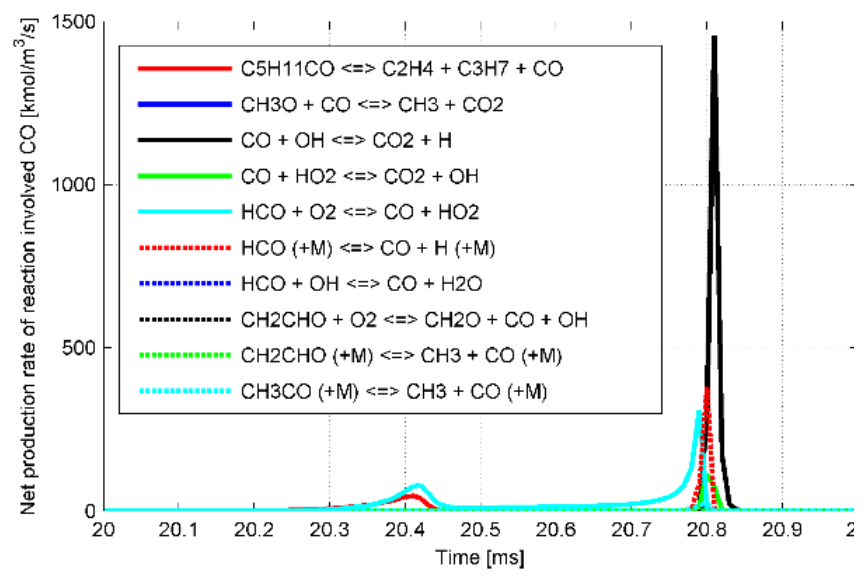

(c)

Figure 11. Chemical kinetics of $\mathrm{CO}$ emission during the combustion processes shown in Fig. 8 ((a) $\Omega=0.4$, (b) $\Omega=0.7$, (c) $\Omega=1.0$ ).

In reality, measured $\mathrm{CO}$ emission could be higher than the prediction of the simulations in the fuel-lean condition. This discrepancy is mainly caused by the partially oxidation of the fuel emerging from the crevices in the combustion chamber or from the oil layer on the engine wall [17]. The piston trajectory in the FPE can be further designed to deal with these issues by generating various flow field inside the cylinder and further reduces $\mathrm{CO}$ emissions. The detailed research is out of the scope of this paper but will be investigated in the future. 


\subsection{NOx Emission}

The predominant composition, over $90 \%$, of $\mathrm{NOx}$ emissions within the engine exhaust is nitric oxide (NO), while nitrogen dioxide $\left(\mathrm{NO}_{2}\right)$ and nitrous oxide $\left(\mathrm{N}_{2} \mathrm{O}\right)$ form the rest. Extensive researches have conducted to investigate the formation mechanisms of NOx emissions [47]. Among them, the most widely-used mechanism describing the NOx production from the practical engine in fuel-lean condition is the Zeldovich mechanism or so-called "thermal mechanism" [46], which is included in the employed reduced n-heptane reaction mechanism.

In the Zeldovich mechanism, the NOx emission is represented as the $\mathrm{NO}$ and the majority of the NO is formed by the oxidation of nitrogen under high in-cylinder temperature. The governing elementary reactions predicting this mechanism are shown as bellow:

$$
\begin{aligned}
\mathrm{O}+\mathrm{N}_{2} & \leftrightarrow \mathrm{NO}+\mathrm{N} \\
\mathrm{N}+\mathrm{O}_{2} & \leftrightarrow \mathrm{NO}+\mathrm{O} \\
\mathrm{N}+\mathrm{OH} & \leftrightarrow \mathrm{NO}+\mathrm{H}
\end{aligned}
$$

The corresponding reaction rates of these three reactions can be found in [47]. Among these three reactions, the reaction (15) works as the initial reaction for the NO formation by generating the radical species N. Additionally, the NO formation rate at low temperature is much slower compared to the typical combustion rate and therefore most of NO is assumed to be produced after the completion of combustion [46]. Such a character implies that NO formation mechanism can be decoupled with the main combustion mechanism and it is possible to deal with the NOx emission after the combustion completes.

There are four factors substantially affecting the NO production in practical engines: air-fuel ratio, in-cylinder temperature, in-cylinder pressure and engine speed. The reason of air-fuel ratio is obvious since leaner air-fuel mixture indicates more nitrogen and oxygen are involved in the combustion process which increases the likelihood of generating NO. On the other hand, high temperature and high pressure in combustion chamber speed up the rates of corresponding reactions and low engine speed extends the time for reactions which inevitable enhances the NO production. In addition, it is widely-accepted that among of these four, in-cylinder temperature is the dominant one to determine the amount of NO eventually. The relationship between the temperature and the NO emission can be explained by the characteristic time of $\mathrm{NO}$ formation as below.

Based on the reactions (15) to (17), the production rate of $\mathrm{NO}$ is yielded as:

$$
\begin{aligned}
& \frac{d[N O]}{d t}=k_{15}^{+}[O]\left[N_{2}\right]+k_{16}^{+}[N]\left[O_{2}\right]+k_{17}^{+}[N][O H]- \\
& k_{15}^{-}[N O][N]-k_{16}^{-}[O][N O]-k_{17}^{-}[N O][H]
\end{aligned}
$$

where [ ] represents the species molar concentration, $\mathrm{k}_{\mathrm{i}}^{+}$and $\mathrm{k}_{\mathrm{i}}^{-}$ show the forward and reverse reaction rates of the corresponding reactions.

By assuming species $\mathrm{N}$ being on the quasi-steady state, (18) can be further simplified as:

$$
\frac{d[N O]}{d t}=2 k_{15}^{+}[O]\left[N_{2}\right] \frac{1-[N O]^{2} /\left(K\left[O_{2}\right]\left[N_{2}\right]\right)}{1+k_{15}^{-}[N O] /\left(k_{16}^{+}\left[O_{2}\right]+k_{17}^{+}[O H]\right)}
$$

where $K=\left(k_{15}^{+} / k_{15}^{-}\right)\left(k_{16}^{+} / k_{16}^{-}\right)$

Since the majority of NO is produced after the completion of combustion, it is appropriate to approximate the concentrations of each species in (19) as the corresponding equilibrium values at the local in-cylinder pressure and temperature. Besides, at the very beginning of the NO formation process, the concentration of NO should be much less than the concentration of other stable species, like $\mathrm{O}_{2}$ and $\mathrm{N}_{2}$. Using these two assumptions, the initial NO production rate can be simplified as:

$$
\left.\frac{d[N O]}{d t}\right|_{\text {initial }}=2 k_{15}^{+}[O]_{e}\left[N_{2}\right]_{e}
$$

The equilibrium value of species $[\mathrm{O}]_{\mathrm{e}}$ can be derived based on the equilibrium constant of the following reaction: [17]

$$
\frac{1}{2} \mathrm{O}_{2} \leftrightarrow O
$$

and finally, the initial production rate of $\mathrm{NO}$ is derived as:

$$
\left.\frac{d[N O]}{d t}\right|_{\text {initial }}=\frac{6 \times 10^{16}}{T^{1 / 2}} \exp \left(\frac{-69090}{T}\right)\left[O_{2}\right]_{e}^{1 / 2}\left[N_{2}\right]_{e}
$$

which is consistent with the result in [47].

The characteristic time for the NO formation can be calculated as below:

$$
\tau_{N O}=\frac{[N O]_{e}}{d[N O] /\left.d t\right|_{\text {initial }}}
$$

Additionally, $[\mathrm{NO}]_{\mathrm{e}}$ can be yielded as: [17]

$$
[N O]_{e}=4.5 \exp \left(-\frac{10825}{T}\right)\left[O_{2}\right]_{e}^{1 / 2}\left[N_{2}\right]_{e}^{1 / 2}
$$

Plugging (22) and (24) into (23), the expression of characteristic time for the NO formation is finally derived as:

$$
\tau_{N O}=\frac{8 \times 10^{-16} T \exp (58300 / T)}{p^{1 / 2}}
$$

As shown in (25), the characteristic time is determined by the in-cylinder gas temperature and pressure. However, the temperature is more important due to its exponential term in (25). Fig. 12 illustrates this conclusion. Obviously, the characteristic time of NO formation is more sensitive to the incylinder temperature since $200 \mathrm{~K}$ increase in temperature reduces one order of magnitude of the characteristic time. Additionally, due to the fact that a typical engine cycle lasts less than $100 \mathrm{~ms}$, the NO generation is only considerable when the in-cylinder temperature is over $2000 \mathrm{~K}$. 


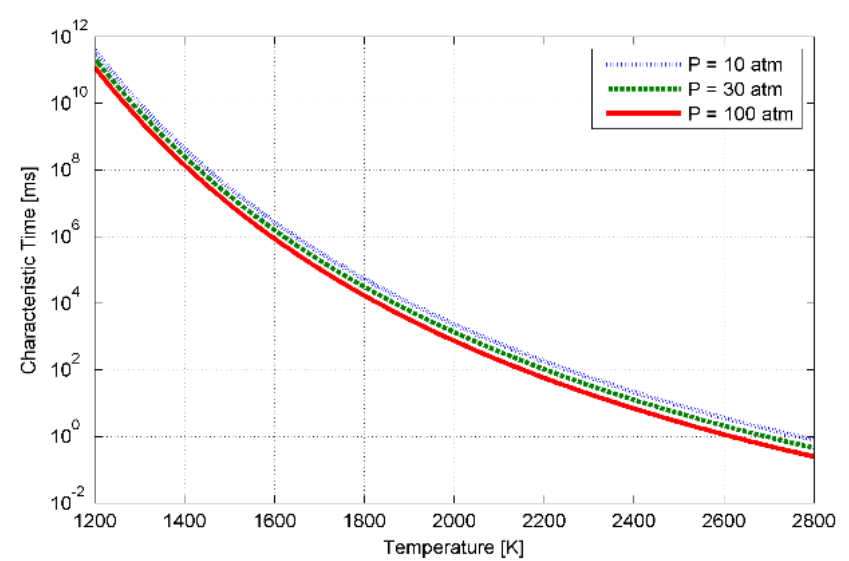

Figure 12. Characteristic time of NO formation in log scale at various incylinder pressure and temperature.

As mentioned in the last section, the piston trajectories in Fig. 5 are within the asymmetric pattern while the compression process and expansion process are different to each other which generate significant effects on the combustion performance in terms of NOx emission. Therefore the corresponding emissions performances are under investigated.

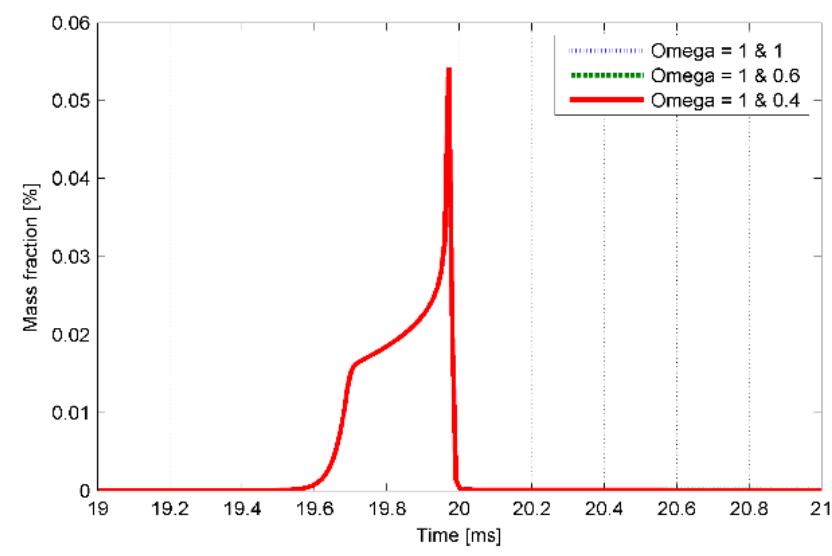

(a)

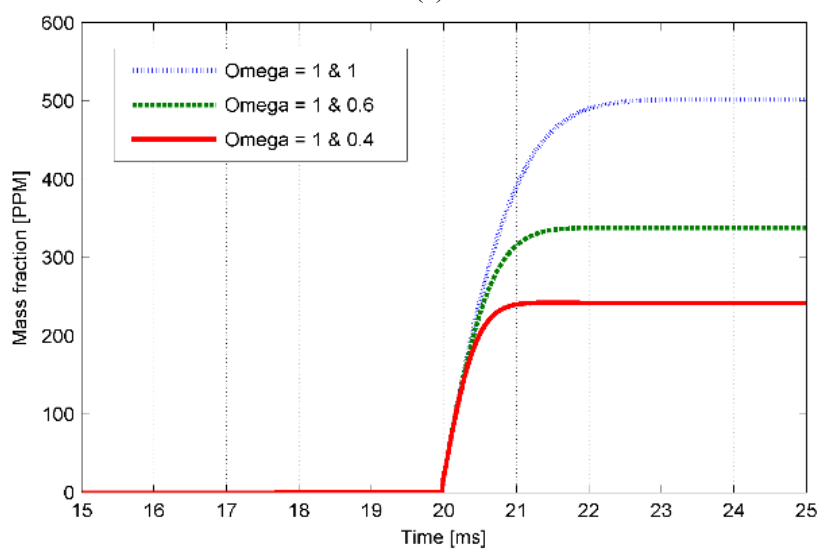

(b)

Figure 13. CO concentration (a) and NOx concentration (b) traces from the combustion processes along the piston trajectories in Fig. 5.

Fig. 13 shows the $\mathrm{CO}$ and the NOx emissions traces during the combustion processes in Fig. 9 respectively. From Fig. 13(a), it is evident that all the $\mathrm{CO}$ molecules are oxidized to $\mathrm{CO}_{2}$ at the TDC point $(20 \mathrm{~ms})$ in each case which implies the completion of the combustion. Furthermore, the majority production of NOx indeed begins after the TDC point in each case (Fig. 13(b)), which supports the assumption that NOx formation mechanism can be decoupled with the main combustion chemical kinetics due to its relatively lower reaction rate at low temperature. In addition, the NOx emission is almost reduced by half (from $500 \mathrm{ppm}$ to $240 \mathrm{ppm}$ ) due to the quicker expansion in the solid line compared to the other two. The result is intuitive from the perspective of the chemical kinetics since rapid expansion reduces both the temperature and the pressure in the cylinder and therefore inhibits the formation of NOx afterwards. Additionally, the sudden expansion also increases the combustion chamber volume quickly, which reduces the species concentration involved the reactions and the rates of NOx formation reactions as well. As can be seen in Fig. 14, the third case, where $\Omega=1.0 \& 0.4$, not only possesses much smaller production rates of each reactions, but also has relatively shorter reaction period for active NOx production. More importantly, this NOx emission reduction is achieved without sacrificing on the engine thermal efficiency (in Fig. 9), which further demonstrates the advantages of the trajectory-based combustion control on emissions control.

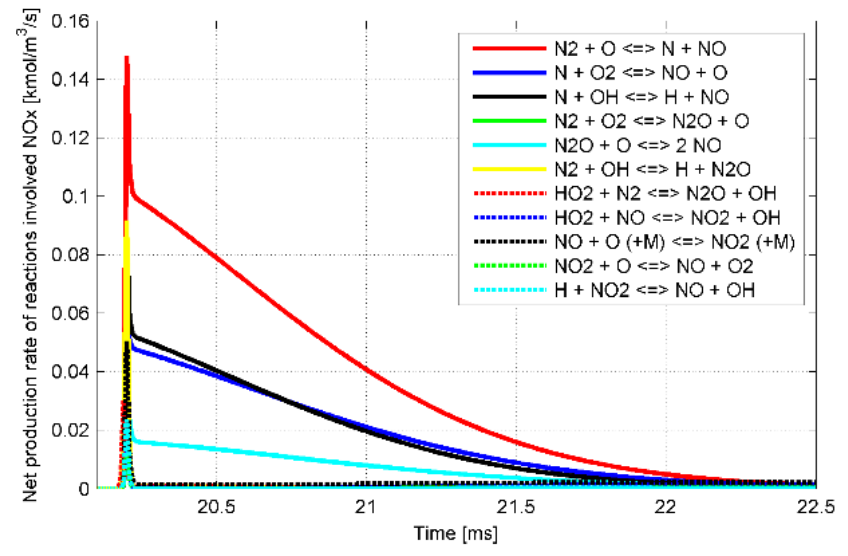

(a)

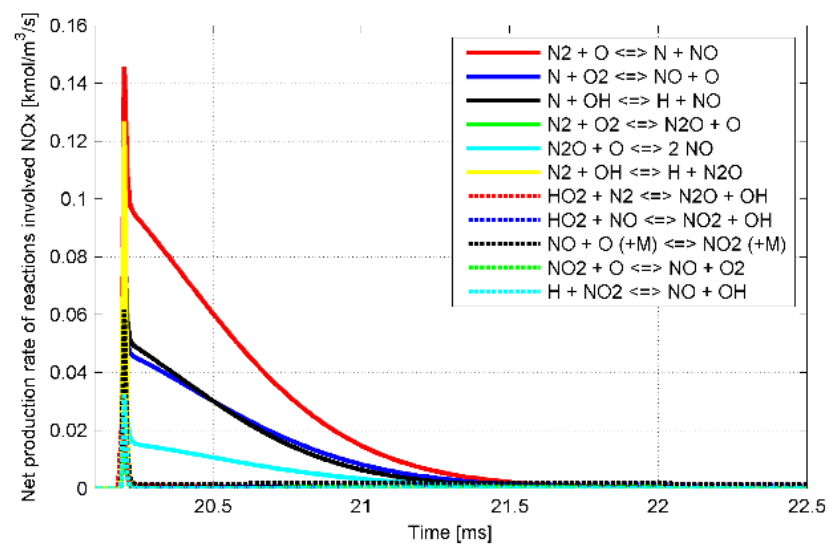

(b) 


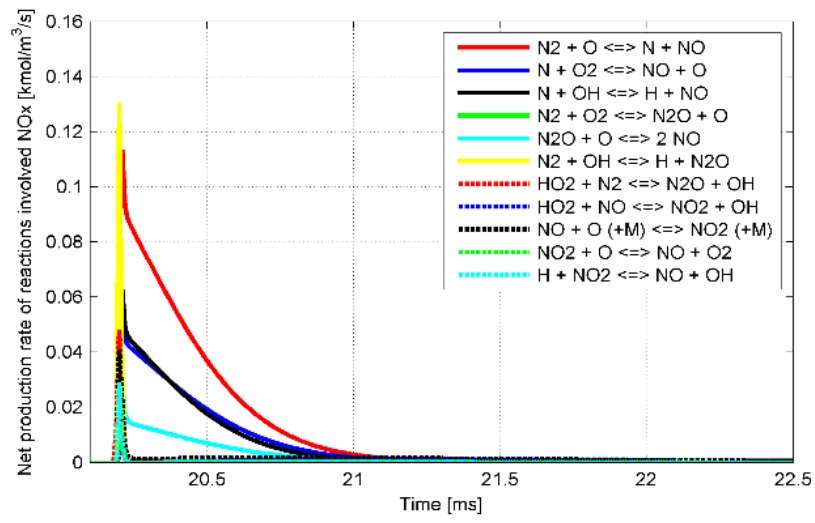

(c)

Figure 14. Chemical kinetics of $\mathrm{CO}$ emission during the combustion processes in Fig. 9 ((a) $\Omega=1 \& 1$, (b) $\Omega=1 \& 0.6$, (c) $\Omega=1 \& 0.4$ ).

\subsection{Optimal asymmetric piston trajectories at different working conditions.}

In order to further elaborate the emission and efficiency benefits by applying asymmetric piston trajectories in FPE, 3D maps are generated indicating the work output and NOx emissions along different asymmetric piston trajectories. In these 3D maps, each point at the $\mathrm{x}-\mathrm{y}$ plain represents the two $\Omega \mathrm{s}$ showing the compression and expansion process respectively. In addition, the $\mathrm{z}$ values show the corresponding work output or NOx emissions. A typical example that the FPE works at $\mathrm{CR}=12$ and AFER $\lambda=2.0$, is shown in Fig. 15.

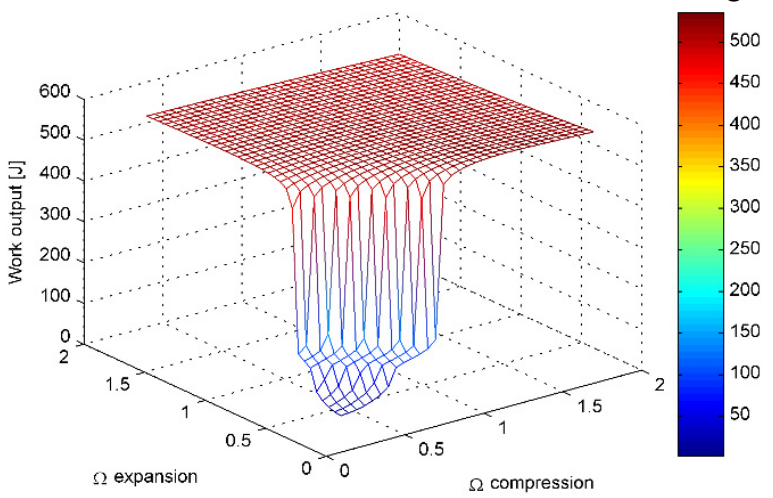

(a)

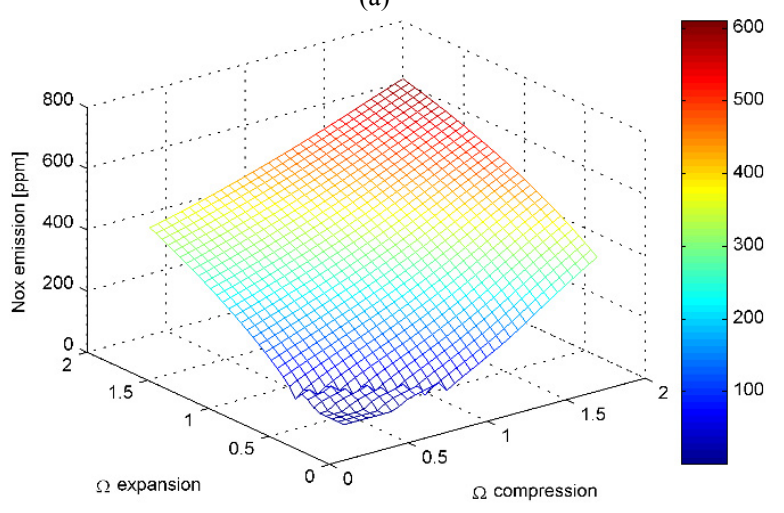

(b)

Figure 15. 3D maps of FPE performance along different piston trajectories at $\mathrm{CR}=12$ and AFER $\lambda=2.0$ ((a) work output, (b) NOx emission).

Besides, by checking the simulation results along the diagonal line in the two $\Omega$ s domain, the performances of FPE deploying symmetric piston trajectories can be achieved as well. Table 3 lists the comparison of FPE performance by applying the optimal asymmetric piston trajectory and the optimal symmetric piston trajectory respectively.

Table. 3 FPE performance comparison between the optimal asymmetric and symmetric piston trajectories $(\mathrm{CR}=12, \lambda=2.0)$.

\begin{tabular}{|c|c|c|c|c|}
\hline $\begin{array}{c}\Omega \\
\text { compression }\end{array}$ & $\begin{array}{c}\Omega \\
\text { expansion }\end{array}$ & $\begin{array}{c}\text { Work } \\
\text { output }[\mathrm{J}]\end{array}$ & $\begin{array}{c}\text { NOx emission } \\
{[\mathrm{ppm}]}\end{array}$ & $\begin{array}{c}\text { Efficiency } \\
{[\%]}\end{array}$ \\
\hline 1.45 & 0.4 & 535.24 & 137.37 & $52.83 \%$ \\
\hline \hline 0.95 & 0.95 & 523.31 & 192.10 & $51.67 \%$ \\
\hline \hline 1.2 & 0.4 & 528.24 & 64.63 & $52.15 \%$ \\
\hline
\end{tabular}

The first two rows show the optimal asymmetric piston trajectory and the optimal symmetric trajectory at this working condition in terms of maximal work output. As can be seen, using the asymmetric piston trajectory can gain $2.28 \%$ work output and reduce NOx emission by $30 \%$. In addition, by reducing the compression $\Omega$ from 1.45 to 1.2 in asymmetric trajectory (the third row), the NOx emission can be even further reduced by half while its thermal efficiency is still larger than the symmetric one.

More importantly, the efficiency and emission benefits can also be achieved at other working conditions by leveraging the ultimate freedom of piston motion in the FPE and varying the piston trajectory actively. The corresponding results are listed in Table 4 (different $\mathrm{CR}$ ) and Table 5 (different AFER, $\lambda$ ).

Table. 4 FPE performance comparison between the optimal asymmetric and symmetric piston trajectories $(\lambda=2.0$, different $\mathrm{CR})$.

\begin{tabular}{|c|c|c|c|c|}
\hline $\mathrm{CR}$ & $\begin{array}{c}\Omega \\
\text { compression }\end{array}$ & $\begin{array}{c}\Omega \\
\text { expansion }\end{array}$ & $\begin{array}{c}\text { Work } \\
\text { output }[\mathrm{J}]\end{array}$ & $\begin{array}{c}\text { NOx emission } \\
{[\mathrm{ppm}]}\end{array}$ \\
\hline \hline $\mathrm{CR}=11$ & 2 & 0.45 & 507.03 & 41.57 \\
\hline $\mathrm{CR}=11$ & 1.4 & 1.4 & 505.67 & 179.88 \\
\hline \hline $\mathrm{CR}=12$ & 1.2 & 0.4 & 528.24 & 64.63 \\
\hline $\mathrm{CR}=12$ & 0.95 & 0.95 & 523.31 & 192.10 \\
\hline \hline $\mathrm{CR}=13$ & 0.7 & 0.4 & 544.74 & 94.6 \\
\hline $\mathrm{CR}=13$ & 0.65 & 0.65 & 541.96 & 200.08 \\
\hline
\end{tabular}

Table. 5 FPE performance comparison between the optimal asymmetric and symmetric piston trajectories $(\mathrm{CR}=12$, different $\lambda)$.

\begin{tabular}{|c|c|c|c|c|}
\hline AFER & $\begin{array}{c}\Omega \\
\text { compression }\end{array}$ & $\begin{array}{c}\Omega \\
\text { expansion }\end{array}$ & $\begin{array}{c}\text { Work } \\
\text { output [J] }\end{array}$ & $\begin{array}{c}\text { NOx emission } \\
{[\mathrm{ppm}]}\end{array}$ \\
\hline \hline$\lambda=2.5$ & 1.3 & 0.4 & 434.24 & 3.74 \\
\hline$\lambda=2.5$ & 0.95 & 0.95 & 426.31 & 6.1 \\
\hline \hline$\lambda=2.0$ & 1.2 & 0.4 & 528.24 & 64.63 \\
\hline$\lambda=2.0$ & 0.95 & 0.95 & 523.31 & 192.10 \\
\hline \hline$\lambda=1.5$ & 1.75 & 0.4 & 680.15 & 3500 \\
\hline$\lambda=1.5$ & 1.2 & 1.2 & 664.56 & 6800 \\
\hline
\end{tabular}

In Table 4 and Table 5, the red data represent the optimal asymmetric piston trajectories at each working condition. It is quite clear that by actively varying the two $\Omega$ s according to different working condition, the FPE gains more output work and produces less NOx emission simultaneously compared to the outcome from the symmetric trajectory. Enlightened by this observation, it is reasonable to claim that the performance of FPE can be improved significantly in the entire load domain via the trajectory-based combustion control. 


\subsection{Sensitivity analysis of the trajectory-based \\ combustion control.}

Usually, the attainable range of $\Omega$ in the FPE is limited mainly by the actuation system, such as the peak actuation force or the dynamic behavior of actuators [43]. However, deploying the piston trajectory within this physically available range may still not guarantee the occurrence of the combustion. For example, smaller $\Omega$ at lower CR may not provide sufficiently long period of high temperature to ignite the air fuel mixture and trigger the combustion. As a result, a socalled combustion available range of $\Omega$, within the physically available range, also exists. Furthermore, unlike the physical one, the combustion available range of $\Omega$ is varied depend on different working conditions, such as the CR and the AFER. The corresponding simulation results are shown in Fig. 16 and Fig. 17.

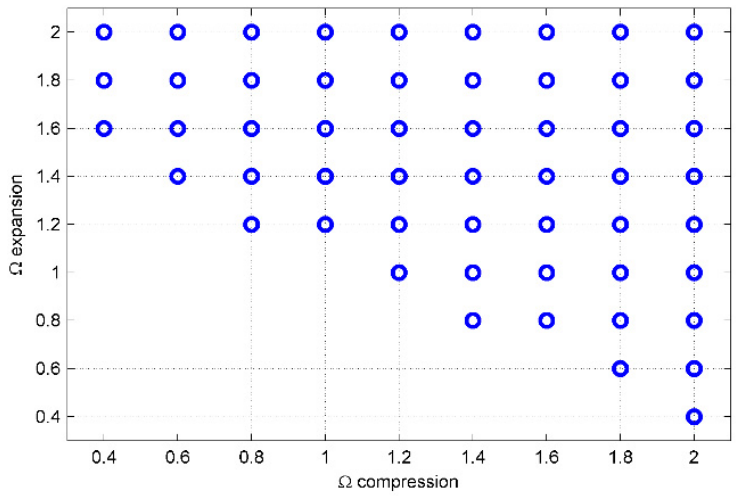

(a)

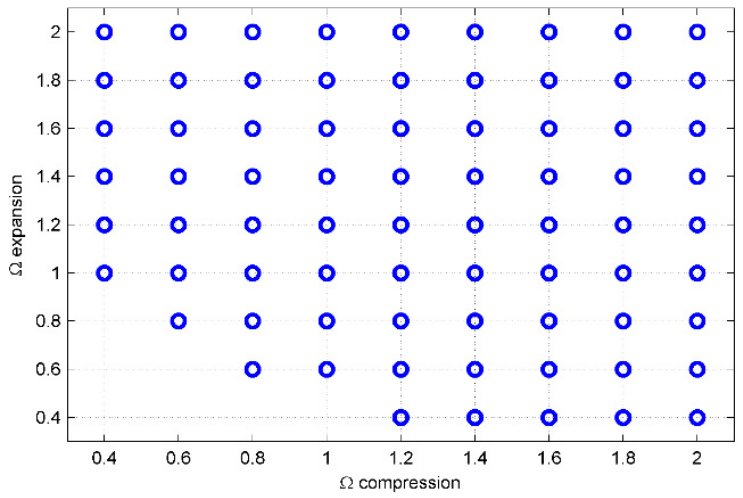

(b)

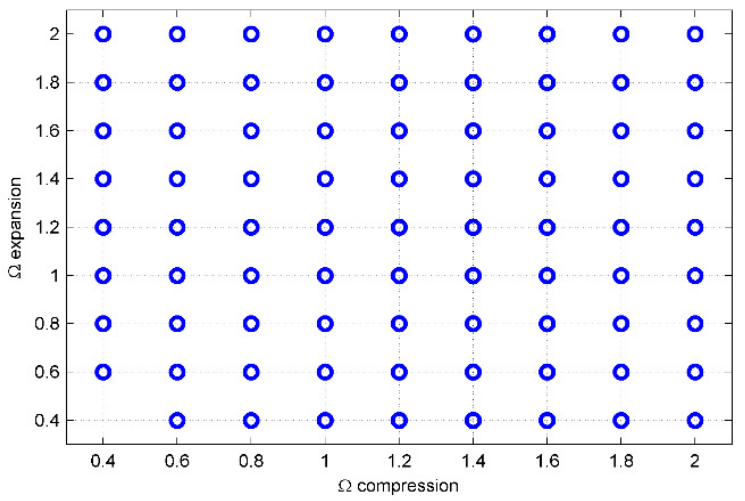

(c)

Figure 16. Combustion available ranges of $\Omega$ at different $\mathrm{CR}$ and $\lambda=2.0$ ((a) $\mathrm{CR}=11$, (b) $\mathrm{CR}=12$, (c) $\mathrm{CR}=13$ ).
Fig. 16 represents the combustion available ranges of $\Omega$ at different CR and identical AFER. Each circle point in the figures indicates the piston trajectory triggering the combustion successfully. It is quite intuitive that increasing the CR enlarges the combustion available range of $\Omega$. Enlightened by this observation, in order to ensure the combustion indeed occurring in the FPE, the applied piston trajectory has to be selected from the combustion available range of $\Omega$ while $\mathrm{CR}=11$.

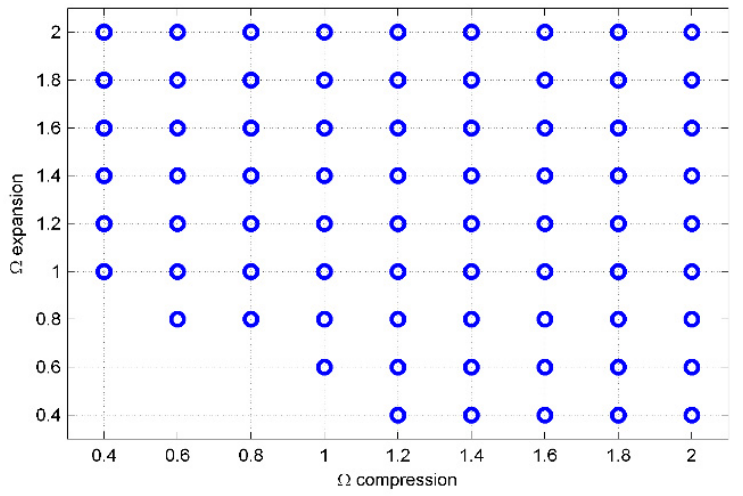

(a)

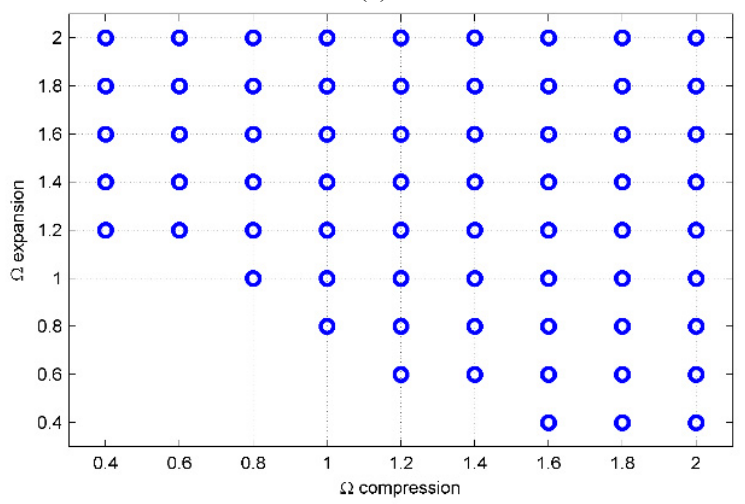

(b)

Figure 17. Combustion available ranges of $\Omega$ at different $\lambda$ and $\mathrm{CR}=12$ ((a) $\lambda$ $=2.5$, (b) $\lambda=1.5$ ).

Similarly, the combustion available ranges of $\Omega$ are also varied according the AFER, as shown in Fig. 17. Obviously, lower AFER reduces the range of $\Omega$. This phenomenon can be explained by the larger heat capacity possessed by the fuel molecules, and richer fuel in the air fuel mixture requires the piston locating around the TDC point for longer duration to increase the in-cylinder temperature high enough and trigger the combustion [48]. Therefore, in order to ensure the occurrence of combustion regardless of the disturbance of AFER, the piston trajectory has to be chosen from the combustion available range of $\Omega$ at lower AFER as well.

\subsection{Comparison of FPE with conventional ICE}

A comparison of engine indicated thermal efficiency and NOx emission between a conventional ICE and a FPE with the optimal piston trajectories are presented in this subsection to further illustrate the advantages of the piston trajectory-based combustion control. Specifically, the piston trajectory of the crankshaft engine is generated through the slider-crank mechanism. Detailed information on these trajectories can be 
found in [43]. On the other hand, the optimal piston trajectories in FPE under different compression ratio are all asymmetric piston trajectories. Their compression section are determined to ignite the combustion at the TDC point and their expansion processes are designed to decrease the production of NOx.

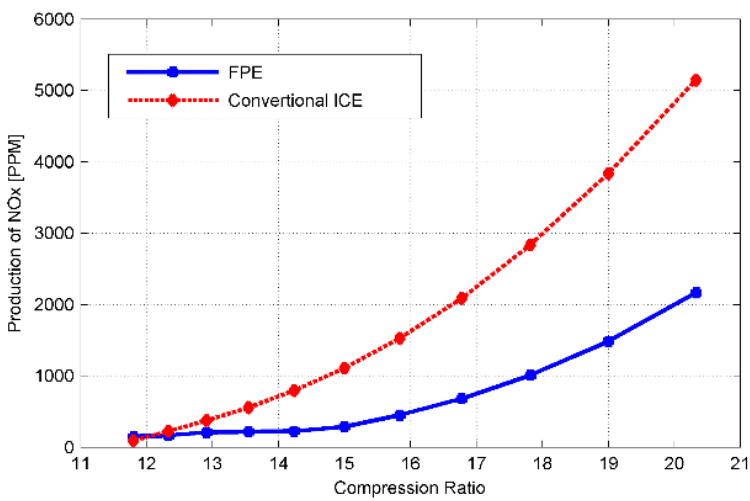

(a)

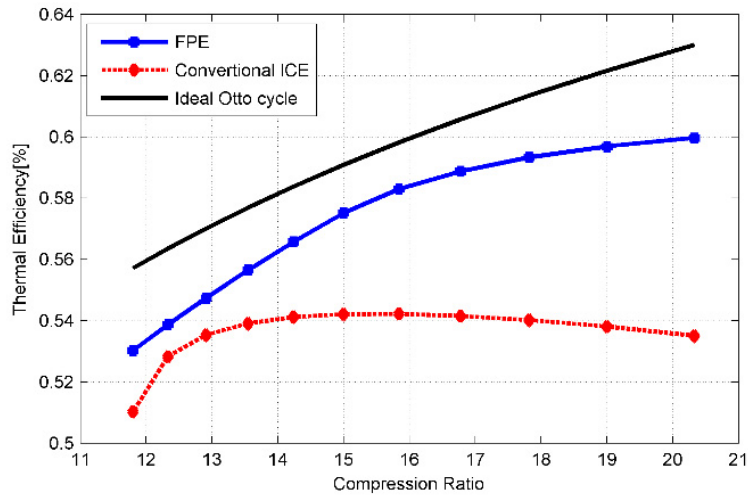

(b)

Figure 18. Comparison between FPE and conventional ICE under different compression ratio ((a) production of NOx emission, (b) Indicated thermal efficiency).

As can be seen in Fig. 18 (a), due to the freedom of the piston motion in FPE, the NOx emission from the FPE are always lower compared to the output of the ICE, except at CR $=11.8$ while the combustion in the ICE is uncompleted. Additionally, the benefit of NOx reduction is further enhanced at the high compression ratio condition. Such result is intuitive since the piston motion of the FPE can be adjusted actively to adapt to different working conditions, e.g. high compression ratio. In addition, by using the same optimal piston trajectories, the indicated thermal efficiency from the FPE are also higher than the counterpart of ICE, as shown in Fig. 18(b). In other words, besides the benefits of emission performance, the FPE with optimal asymmetric piston trajectories can also increase the engine efficiency simultaneously across the entire compression ratio domain, which is consistent with our aforementioned analysis.

\section{Conclusion}

In this paper, the benefit of the trajectory-based combustion control on emissions reduction is presented. Enabled by the FPE, the trajectory-based combustion control is able to manipulate the in-cylinder temperature trace and affect the chemical kinetics of the combustion, including the generation processes of different emissions. A comprehensive model is then developed to reproduce the combustion processes along different piston trajectories. The simulation results clearly show that both $\mathrm{CO}$ and NOx can be reduced by implementing appropriate piston trajectories in the FPE. Specifically, unique asymmetric trajectories are designed that decreases the amount of NOx emission and increases the engine thermal efficiency simultaneously. Meanwhile sensitivity analyses are conducted at different working conditions to demonstrate the robustness of this advanced combustion control method. In addition, the performance of the FPE is also compared to the conventional ICE in terms of indicated thermal efficiency and NOx emission production which further demonstrates the advantages of the piston trajectory-based combustion control. Considering the fact that the production of emission species are mainly driven by the chemical kinetics, the emission benefits from the trajectorybased combustion control can be readily extended to other emission species in different combustion modes. Moreover, optimal piston trajectories can be further generated using more rigorous optimization method by taking the chemical kinetics of the utilized fuel and the loading dynamics into account.

\section{Acknowledgments}

The authors would like to thank the NSF Center for Compact and Efficient Fluid Power (CCEFP) for the financial support (EEC-0540834) and Ford Motor Company for donating the free piston engine.

\section{Appendix}

Full Chemical Kinetics of CO within Applied Reaction Mechanism in the Proposed Model

\begin{tabular}{|c|l|}
\hline Index & Elementary Reactions \\
\hline \hline 1 & $\mathrm{C} 5 \mathrm{H} 11 \mathrm{CO}<=>\mathrm{C} 2 \mathrm{H} 4+\mathrm{C} 3 \mathrm{H} 7+\mathrm{CO}$ \\
\hline 2 & $\mathrm{CH} 2+\mathrm{O} 2<=>\mathrm{CO}+\mathrm{H} 2 \mathrm{O}$ \\
\hline 3 & $\mathrm{CH} 2+\mathrm{O} 2<=>\mathrm{CO}+\mathrm{H}+\mathrm{OH}$ \\
\hline 4 & $\mathrm{CH} 3 \mathrm{O}+\mathrm{CO}<=>\mathrm{CH} 3+\mathrm{CO} 2$ \\
\hline 5 & $\mathrm{CO}+\mathrm{OH}<=>\mathrm{CO} 2+\mathrm{H}$ \\
\hline 6 & $\mathrm{CO}+\mathrm{O}(+\mathrm{M})<=>\mathrm{CO} 2(+\mathrm{M})$ \\
\hline 7 & $\mathrm{CO}+\mathrm{O} 2<=>\mathrm{CO} 2+\mathrm{O}$ \\
\hline 8 & $\mathrm{CO}+\mathrm{HO} 2<=>\mathrm{CO} 2+\mathrm{OH}$ \\
\hline 9 & $\mathrm{HCO}+\mathrm{O} 2<=>\mathrm{CO}+\mathrm{HO} 2$ \\
\hline 10 & $\mathrm{HCO}(+\mathrm{M})<=>\mathrm{CO}+\mathrm{H}(+\mathrm{M})$ \\
\hline 11 & $\mathrm{C} 2 \mathrm{H} 3+\mathrm{HCO}<=>\mathrm{C} 2 \mathrm{H} 4+\mathrm{CO}$ \\
\hline 12 & $\mathrm{C} 2 \mathrm{H} 2+\mathrm{O}<=>\mathrm{CH} 2+\mathrm{CO}$ \\
\hline 13 & $\mathrm{C} 2 \mathrm{H} 2+\mathrm{OH}<=>\mathrm{CH} 3+\mathrm{CO}$ \\
\hline 14 & $\mathrm{CH} 2 \mathrm{O}(+\mathrm{M})<=>\mathrm{CO}+\mathrm{H} 2(+\mathrm{M})$ \\
\hline 15 & $\mathrm{HCO}+\mathrm{OH}<=>\mathrm{CO}+\mathrm{H} 2 \mathrm{O}$ \\
\hline & \\
\hline &
\end{tabular}




\begin{tabular}{|c|c|}
\hline 16 & $\mathrm{HCO}+\mathrm{O}<=>\mathrm{CO}+\mathrm{OH}$ \\
\hline 17 & $\mathrm{CH} 2 \mathrm{CHO}+\mathrm{O} 2<=>\mathrm{CH} 2 \mathrm{O}+\mathrm{CO}+\mathrm{OH}$ \\
\hline 18 & $\mathrm{CH} 2 \mathrm{CO}+\mathrm{H} \Leftrightarrow=\mathrm{CH} 3+\mathrm{CO}$ \\
\hline 19 & $\mathrm{CH} 2 \mathrm{CO}(+\mathrm{M})<=>\mathrm{CH} 2+\mathrm{CO}(+\mathrm{M})$ \\
\hline 20 & $\mathrm{CH} 2 \mathrm{CO}+\mathrm{OH}<\Rightarrow \mathrm{CH} 3 \mathrm{O}+\mathrm{CO}$ \\
\hline 21 & $\mathrm{H}+\mathrm{HCO}<=>\mathrm{CO}+\mathrm{H} 2$ \\
\hline 22 & $2 \mathrm{HCO}=>2 \mathrm{CO}+\mathrm{H} 2$ \\
\hline 23 & $2 \mathrm{HCO}<=>\mathrm{CH} 2 \mathrm{O}+\mathrm{CO}$ \\
\hline 24 & $\mathrm{CH} 2 \mathrm{CHO}(+\mathrm{M})<=>\mathrm{CH} 3+\mathrm{CO}(+\mathrm{M})$ \\
\hline 25 & $\mathrm{CH} 3 \mathrm{CO}(+\mathrm{M})<=>\mathrm{CH} 3+\mathrm{CO}(+\mathrm{M})$ \\
\hline 26 & $\mathrm{HOCHO} \Leftrightarrow=>\mathrm{CO}+\mathrm{H} 2 \mathrm{O}$ \\
\hline 27 & $\mathrm{HOCHO}+\mathrm{OH}=>\mathrm{CO}+\mathrm{H} 2 \mathrm{O}+\mathrm{OH}$ \\
\hline 28 & $\mathrm{H}+\mathrm{HOCHO}=>\mathrm{CO}+\mathrm{H} 2+\mathrm{OH}$ \\
\hline 29 & $\mathrm{HO} 2+\mathrm{HOCHO}=>\mathrm{CO}+\mathrm{H} 2 \mathrm{O} 2+\mathrm{OH}$ \\
\hline 30 & $\mathrm{HOCHO}+\mathrm{O} \Rightarrow \mathrm{CO}+2 \mathrm{OH}$ \\
\hline 31 & $\mathrm{CH} 2 \mathrm{CO}+\mathrm{OH}<=>\mathrm{CH} 2 \mathrm{OH}+\mathrm{CO}$ \\
\hline 32 & $\mathrm{C} 3 \mathrm{H} 7 \mathrm{CO}<=>\mathrm{C} 3 \mathrm{H} 7+\mathrm{CO}$ \\
\hline 33 & $\mathrm{C} 2 \mathrm{H}+\mathrm{OH}<=>\mathrm{CH} 2+\mathrm{CO}$ \\
\hline 34 & $\mathrm{C} 3 \mathrm{H} 2+\mathrm{O}<=>\mathrm{C} 2 \mathrm{H}+\mathrm{CO}+\mathrm{H}$ \\
\hline 35 & $\mathrm{C} 4 \mathrm{H} 2+\mathrm{O}<=>\mathrm{C} 3 \mathrm{H} 2+\mathrm{CO}$ \\
\hline 36 & $\mathrm{C} 3 \mathrm{H} 2+\mathrm{OH}<=>\mathrm{C} 2 \mathrm{H} 2+\mathrm{CO}+\mathrm{H}$ \\
\hline 37 & $\mathrm{C} 3 \mathrm{H} 3+\mathrm{O}<=>\mathrm{C} 2 \mathrm{H} 2+\mathrm{CO}+\mathrm{H}$ \\
\hline 38 & $\mathrm{C} 5 \mathrm{H} 5+\mathrm{O}<=>\mathrm{C} 4 \mathrm{H} 5+\mathrm{CO}$ \\
\hline 39 & $\mathrm{C} 6 \mathrm{H} 5 \mathrm{O}<=>\mathrm{C} 5 \mathrm{H} 5+\mathrm{CO}$ \\
\hline 40 & $\mathrm{~A} 1-+\mathrm{O}<=>\mathrm{C} 5 \mathrm{H} 5+\mathrm{CO}$ \\
\hline 41 & $\mathrm{~A} 1 \mathrm{C} 2 \mathrm{H} 3+\mathrm{O}<=>\mathrm{A} 1-+\mathrm{CH} 3+\mathrm{CO}$ \\
\hline 42 & $\mathrm{~A} 3-+\mathrm{O} 2<=>\mathrm{A} 2 \mathrm{R} 5+\mathrm{CO}+\mathrm{HCO}$ \\
\hline
\end{tabular}

\section{References}

[1] Kampa, M. and Castanas, E., "Human Health Effects of Air Pollution", Environmental Pollution, Vol. 151, Issue. 2, pp. 362-367, Jan 2008.

[2] Mauzerall, D. L., Sultan, B., Kim, N. and Bradford D. F. "NOx Emissions from Large Point Sources: Variability in Ozone Production, Resulting Health Damages and Economic Costs", Atmospheric Environment, Vol. 39, Issue. 16, pp. 2851-2866, May 2005.

[3] "Light-Duty Vehicles and Trucks and Motorcycles Emission Regulation" provided by the United States Environmental Protection Agency. http://www.epa.gov/otaq/standards/light-duty/index.htm

[4] "European Emission Standards" provided by the European Parliament, Council. http://en.wikipedia.org/wiki/European_emission_standards

[5] Cho, H.M. and He, B. Q., "Spark Ignition Natural Gas Engines - A Review", Energy Conversion and Management, Vol. 48, Issue. 2, pp. 608-618, Feb. 2007.

[6] Alasfour, F. N., "NOx Emission from a Spark Ignition Engine Using 30\% Iso-butanol-gasoline Blend: Part 2-Ignition Timing", Applied Thermal Engineering, Vol. 18, Issue. 8, pp. 609-618, Aug 1998.

[7] Ma, F., Liu, H., Wang, Y., Li, Y., Wang, J. and Zhao, S., "Combustion and Emission Characteristics of a Port-injection HCNG Engine under Various Ignition Timings", International Journal of Hydrogen Energy, Vol. 33, Issue. 2, pp. 816-822, Jan 2008.

[8] Pierpont, D., Montgomery, D. and Reitz, R., "Reducing Particulate and
NOx Using Multiple Injections and EGR in a D.I. Diesel", $S A E$ Technical Paper 950217, Feb, 1995.

[9] Hountalas, D. T., Mavropoulos, G. C. and Binder, K. B., "Effect of Exhaust Gas Recirculation (EGR) Temperature for Various EGR Rates on Heavy Duty DI Diesel Engine Performance and Emission", Energy, Vol. 33, Issue. 2, pp. 272-283, Feb 2008.

[10] Maiboom, A., Tauzia, X. and Hetet, J., "Experimental Study of Various Effects of Exhaust Gas Recirculation (EGR) on Combustion and Emissions of an Automotive Direct Injection Diesel Engine", Energy, Vol.33, Issue. 1, pp. 22-34, Jan 2008.

[11] Gu, X., Huang, Z., Cai, J., Gong, J., Wu. X. and Lee, C., "Emission Characteristics of a Spark-ignition Engine Fuelled with Gasoline-nbutanol Blends in Combination with EGR", Fuel, Vol. 93, pp. 611-617, Mar 2012.

[12] Han, Z., Uludogan, A., Hampson, G. and Reitz, R., "Mechanism of Soot and NOx Emission Reduction Using Multiple-injection in a Diesel Engine", SAE Technical Paper 960633, Feb, 1996.

[13] Tow. T., Pierpont, D. and Reitz, R. D., "Reducing Particulate and NOx Emissions by Using Multiple Injections in a Heavy Duty D.I. Diesel Engine”, SAE Technical Paper 940897, Mar 1994.

[14] Choi, C. Y. and Reitz, R. D., "An Experimental Study on the Effects of Oxygenated Fuel Blends and Multiple Injection Strategies on DI Diesel Engine Emissions", Fuel, Vol. 78, Issue. 11, pp. 1303-1317, Sep 1999.

[15] Adi, G., Hall, C. M., Snyder, D. B., Belt, B. W. D. and Shaver, G. M, "Fuel-Flexible Engine Control of Biodiesel Blends During MixingControlled Combustion", Journal of Dynamics Systems, Measurement, and Control, Vol.135, Issue 7, 061017, Aug. 2013.

[16] Stone, R., (1999). Introduction to Internal Combustion Engines", Basingstoke, UK.

[17] J. Heywood, (1988). Internal Combustion Engine Fundamentals, McGraw-Hill

[18] Weilenmann, M., Favez, Y. and Alvarez, R., "Cold-start Emissions of Modern Passenger Cars at Different Low Ambient Temperatures and Their Evolution over Vehicle Legislation Categories", Atmospheric Environment, Vol. 43, Issue. 15, pp. 2419-2429, May 2009.

[19] Henein, N. A and Tagomori, M. K., "Cold-start Hydrocarbon Emissions in Port-injected Gasoline Engines", Progress in Energy and Combustion Science, Vol. 25, Issue. 6, pp. 563-593, Dec. 1999.

[20] Salehi, R., Shahbakhti, M. and Hedrick, J. K., "Real-time Hybrid Switching Control of Automotive Cold Start Hydrocarbon Emission", Journal of Dynamics Systems, Measurement, and Control, Vol. 136, Issue. 4, 041002, Mar 2014

[21] Su, E. C. and Rothschild, W. G., "Dynamic Behavior of Three-way Catalysts", Journal of Catalysis, Vol. 99, Issue. 2, pp. 506-510, Jun. 1986 ,

[22] Jackson, R., Peyton Jones, J., Pan, J. and Roberts, J., "Chemical Aspects of the Dynamic Performance of a Three-Way Catalyst", SAE Technical Paper 1999-01-0312, Mar, 1999.

[23] Russel, A. and Epling, W. S., "Diesel Oxidation Catalysts", Catalysis Reviews: Science and Engineering, Vol. 53, Issue. 4, pp. 337-423, Oct 2011.

[24] Stein, H. J, "Diesel Oxidation Catalysts for Commercial Vehicle Engines: Strategies on Their Application for Controlling Particulate Emissions," Applied Catalysis B: Environmental, Vol. 10, Issue. 1-3, pp. 69-82, Sep 1996.

[25] Neeft, J. P., Makkee, M., and Moulijn, J. A., "Diesel Particulate Emission Control", Fuel processing technology, Vol. 47, Issue. 1, pp.169, Apr. 1996.

[26] Van Setten, B. A., Makkee, M., and Moulijn, J. A., "Science and Technology of Catalytic Diesel Particulate Filters", Catalysis Reviews, Vol. 43, Issue. 4, pp. 489-564, 2001.

[27] Koebel, M., Elsener, M., and Kleemann, M., "Urea-SCR: a Promising Technique to Reduce NOx Emissions from Automotive Diesel Engines", Catalysis today, Vol. 59, Issue. 3-4, pp. 335-345, Jun. 2000.

[28] Mikalsen, R. and Roskilly, A. P., "A Review of Free-piston Engine History and Applications", Applied Thermal Engineering, Vol.27, Issue.14-15, pp.2339-2352, Oct 2007.

[29] Van Blarigan, P., Paradiso, N. and Goldsborough, S., "Homogeneous Charge Compression Ignition with a Free Piston: A New Approach to Ideal Otto Cycle Performance", SAE Technic Paper 982484, Oct. 1998.

[30] Somhorst, H. E. and Achten, P. J., "The Combustion Process in a DI Diesel Hydraulic Free Piston Engine", SAE Transaction, Vol.105, 1996.

[31] Kosaka, H., Akita, T., Moriya, K., Goto, S., Hotta, Y., Umeno, T. and Nakakita, K., "Development of Free Piston Engine Linear Generator System Part 1 - Investigation of Fundamental Characteristics", $S A E$ Technical Paper 2014-01-1203, Apr. 2014. 
[32] Goto, S., Moriya, K., Kosaka, H., Akita, T., Hotta, Y., Umeno, T. and Nakakita, K., "Development of Free Piston Engine Linear Generator System Part 2 - Investigation of Control System for Generator", $S A E$ Technical Paper 2014-01-1193, 2014.

[33] Kock, F., Haag, J. and Friedrich, H., "The Free Piston Linear Generator - Development of an Innovative, Compact, Highly Efficient Rangeextender Module", SAE Technical Paper, 2013-01-1727, 2013.

[34] Li, K., Sadighi, A. and Sun, Z., "Active Motion Control of a Hydraulic Free Piston Engine", IEEE/ASME Transaction. Mechatronics, Vol. 19, Issue. 4, pp. 1148-1159, Aug, 2014.

[35] Li, K., Zhang, C. and Sun, Z., "Precise Piston Trajectory Control for a Free Piston Engine", Control Engineering Practice, Vol. 34, pp. 30-38, Jan 2015.

[36] Jia, B., Tian, G., Feng, H., Zuo, Z. and Roskilly, A. P., "An Experimental Investigation into the Starting Process of Free-piston Engine Generator", Applied Energy, Vol. 157, pp. 798-804, 2015.

[37] Feng, H., Guo, C., Yuan, C., Guo, Y., Zuo, Z., Roskilly, A. P. and Jia, B., "Research on Combustion Process of a Free Piston Diesel Linear Generator", Applied Energy, Vol. 161, pp. 395-403, 2016.

[38] Mikalsen, R. and Roskilly, A. P., "The Control of a Free-piston Engine Generator. Part 1: Fundamental Analyses", Applied Energy, Vol. 87, Issue. 4, pp. 1273-1280, 2010.

[39] Mikalsen, R. and Roskilly, A. P., "The Control of a Free-piston Engine Generator. Part 2: Engine Dynamics and Piston Motion Control", Applied Energy, Vol. 87, Issue. 4, pp. 1281-1287, 2010.

[40] Zhao, Z., Zhang, F., Huang, Y., Zhao, C. and Guo, F., "An Experimental Study of the Hydraulic Free Piston Engine", Applied Energy, Vol. 99, pp. 226-233, 2012.

[41] Xu, Z. and Chang, S., "Prototype Testing and Analysis of a Novel Internal Combustion Linear Generator Integrated Power System", Applied Energy, Vol. 87, Issue. 4, pp. 1342-1348, 2010.

[42] Jia, B., Zuo, Z., Feng, H., Tian, G., Smallbone, A. and Roskilly, A. P., "Effect of Closed-loop Controlled Resonance Based Mechanism to Start Free Piston Engine Generator: Simulation and Test Results", Applied Energy, Vol. 164, pp. 532-539, 2016.

[43] Zhang, C., Li, K. and Sun, Z., "Modeling of Piston Trajectory-based HCCI Combustion Enabled by a Free Piston Engine", Applied Energy, Vol. 139, pp. 313-326, Feb, 2015.

[44] Wang, H., Retiz, R. D., Yao, M., Yang, B., Jiao, Q. and Qiu, L., "Development of an n-Heptane-n-butanol-PAH mechanism and its application for combustion and soot prediction", Combustion and Flame, Vol. 160, Issue. 3, pp504-419, Mar 2013.

[45] Goodwin, D., Malaya N. and Speth. R., "Cantera: An Object-oriented Software for Chemical Kinetics, Thermodynamics and Transport Processes", available at https://code.google.com/p/cantera/.

[46] Zeldovich, Y. B., Sadovnikov, P, Y. and Frank-kamenetskii, D. A., "Oxidation of Nitrogen in Combusiton", Academy of Sciences of USSR, Institute of Chemical Physics, Moscow-Leningrad, 1947.

[47] Bowman, C. T. "Kinetic of Pollutant Formation and Destruction in Combustion", Progress in Energy and Combustion Science, Vol. 1, pp. $33-45,1975$.

[48] Aichlmayr, H. T., Kittelson, D. B. and Zachariah, M, R., "Miniature Free-piston Homogeneous Charge Compression Ignition Enginecompressor Concept-Part II: Modeling HCCI Combustion in Small Scales with Detailed Homogeneous Gas Phase Chemical Kinetics", Chemical Engineering Science, Vol. 57, pp. 4173-4186, 2002. 